\title{
Avaliação do processo de compostagem utilizando lodo de Estação de Tratamento de Efluentes de laticínio
}

\author{
The composting process assessment using Wastewater Treatment Plant sludge dairy \\ Alexandre Couto Rodrigues, Camila Angélica Baum, Jessica Formentini, Natana Schmachtenberg, \\ Gabriel Menezes Trevisan, Ana Claudia Guedes Silva \\ Universidade Federal de Santa Maria, Santa Maria, RS, Brasil \\ coutoalexandre@yahoo.com.br; camilabaumm@yahoo.com.br; jeformentini@yahoo.com.br; natana_2005@yahoo.com.br; \\ gabryelmt@hotmail.com; anaa_guedess@hotmail.com
}

\begin{abstract}
Resumo
O estudo avaliou o processo de compostagem utilizando lodo flotado da Estação de Tratamento de Efluentes de Laticínio, a fim de verificar a qualidade do composto final e o valor fertilizante final para aplicabilidade na agricultura. Este foi desenvolvido na área experimental do Colégio Agrícola de Frederico Westphalen/CAFW-UFSM, em Frederico Westphalen na região do Médio Alto Uruguai do Rio Grande do Sul, de abril a julho de 2013. O experimento foi realizado em triplicata, onde cada pilha de compostagem foi constituída por lodo flotado (fonte de nitrogênio) e feno de capim-tifton 85 (fonte de carbono). Durante o processo foi realizado o monitoramento da temperatura, variáveis climatológicas, insetos, fungos, aranhas, minhocas, larvas e odor. Após a maturação do composto também foram realizadas análises químicas dos substratos finais. O desenvolvimento do processo durante o outono/inverno e as ocorrências de períodos chuvosos, fez com que a temperatura das pilhas acompanhasse a temperatura ambiente, somente alcançando temperaturas mais altas nos períodos sem precipitação pluviométrica significativa, impedindo que o processo atingisse a fase termófila. Apesar disso, o substrato resultante apresentou boa relação C/N, 18,67:1, podendo ser usado como fertilizante sem prejuízo ao solo.
\end{abstract}

Palavras-chave: C/N, fertilizante orgânico, fase mesófila, resíduo orgânico.

\begin{abstract}
The study evaluated the composting process using float sludge from Dairy Wastewater Treatment Plant in order to check the quality of the final compound and the value end fertilizer for applicability in agriculture. This was developed in the experimental area of Agricultural College of Frederick / CAFW-UFSM in Fredericksburg in Medium High Uruguay of Rio Grande do Sul region, from April to July 2013. The experiment was performed in triplicate, where each windrow composting comprised float sludge (nitrogen source) and tifton 85 hay (carbon source). During the process was monitor the temperature, climatic variables, insects, fungi, spiders, worms, larvae and odor. After maturation of the chemical analysis of the final composite substrates were also performed. The development of the process during the fall I winter and instances of rainy periods, caused the temperature of cells accompany the room temperature only reaching higher temperatures during periods without significant rainfall, and preventing the process reached the thermophilic stage. Nevertheless, the resulting substrate had good C/N, 18.67: 1, and can be used without prejudice to the soil as fertilizer.
\end{abstract}

Keywords: C/N, organic fertilizer, mesophilic phase, organic residue. 


\section{Introdução}

As atividades agroindustriais e de processamento de produtos agropecuários são de grande expressão no mercado brasileiro, principalmente em termos de sua contribuição para a renda (GUANZIROLI, 2010; PEDROSA et al., 2013). Entretanto, a atividade demanda diversos cuidados, principalmente em relação aos de resíduos gerados nas etapas de processamento, que devido a algumas propriedades adversas ao meio ambiente são necessários cuidados com sua disposição final (MATOS, 2005; FAGUNDES, 2009).

A principal característica dos resíduos de atividades agroindustriais é a alta concentração de material orgânico. Esta é responsável por um dos maiores impactos causados por resíduos sólidos orgânicos, formando ácidos orgânicos através da fermentação do resíduo, causando maus odores, reduzindo o oxigênio dissolvido em águas superficiais e contaminando o solo, quando disposto inadequadamente (GOPINATHAN \& THIRUMURTHY, 2012).

Os efluentes da indústria de laticínios são compostos por quantidades variáveis de leite (perdas durante o processo) e materiais sólidos flutuantes (higienização), como: detergentes, desinfetantes, lubrificantes, areia, água, e esgoto doméstico. A carga poluente deste efluente varia de acordo com a água utilizada, o tipo de processo e o controle sobre a descarga destes resíduos (NIRENBERG \& FERREIRA, 2005). Em muitos laticínios o soro é descartado junto com os demais efluentes, o que aumenta o potencial poluidor devido ao soro ser cem vezes mais poluente que o esgoto doméstico. $\mathrm{O}$ soro, o leitelho e o leite ácido possuem alto valor nutritivo e elevadas cargas orgânicas, sendo sugerido que se faça o tratamento destes de forma separada dos demais efluentes gerados no laticínio (SILVA, 2011).

Devido ao potencial poluidor, a disposição destes resíduos é uma das preocupações dos profissionais que trabalham com a área de saneamento ambiental e das administrações municipais (FAGUNDES, 2009).

Toda e qualquer técnica que visa o aproveitamento de resíduos na alimentação animal ou atividade agrícola é conveniente, em virtude da reciclagem desses nutrientes ser benéfica por possuir altas concentrações de matéria orgânica e nutrientes (MATOS, 2005; PRIMO et al., 2010). Quando o aproveitamento desse resíduo não pode ser in natura, técnicas de tratamento são aplicadas com o intuito de conferir propriedades químicas e físicas vantajosas ao composto. Dentre as técnicas de tratamento de resíduos orgânicos, uma amplamente conhecida e aplicada é a compostagem, principalmente por sua praticidade, baixo custo e pelos resultados positivos obtidos (KIEHL, 2002; INÁCIO \& MILLER, 2009).

A compostagem pode ser considerada como um tratamento único da fração orgânica dos resíduos e ainda pode constituir um processo de tratamento dos resíduos sólidos, integrado num sistema de reciclagem (RUSSO, 2003). Monteiro et al., (2001) definem como compostagem o processo natural de biodegradação controlada de materiais orgânicos de origem animal e vegetal pela ação de microrganismos, transformando resíduos orgânicos em adubo humificado, conhecido como húmus, que requer ar, água, matéria orgânica e micro-organismos (USDA, 2005; PEREIRA NETO, 2007).

Segundo USDA (2005) e Mustapha (2013) a prática da compostagem minimiza a poluição dos recursos hídricos, por evitar a disposição in natura do resíduo nos mesmos. Além disso, a compostagem elimina patógenos, reduz tempo, custo, energia e espaço nos aterros sanitários, melhora a estrutura do solo através do incremento de matéria orgânica e esta, por sua vez, disponibiliza macronutrientes essenciais para a vegetação, como nitrogênio, fósforo e potássio (LONGHURST et al., 2010; FERNANDES \& SILVA, 2006).

A compostagem aeróbia é o processo mais adequado para o tratamento de materiais orgânicos, pois a decomposição é realizada por micro-organismos que sobrevivem em temperaturas de até $70^{\circ} \mathrm{C}$, além dos odores emanados não serem agressivos e a decomposição ocorrer rapidamente (INÁCIO \& MILLER, 2009). No decorrer do processo de compostagem aeróbia, segundo Schalch et al., (2002), dois estágios podem ser identificados: o primeiro é denominado digestão, na qual o material alcança o estado de bioestabilização. $\mathrm{O}$ segundo estágio, o mais longo, é o da maturação, no qual a massa em fermentação atinge a humificação, acompanhada da mineralização de 
determinados componentes da matéria orgânica, como nitrogênio, fósforo, cálcio e magnésio, que passam da forma orgânica para a inorgânica, apresentando características de biofertilizante (KIEHL, 1985; SCHALCH et al., 2002).

O resultado dessa decomposição é um produto rico em húmus e nutrientes minerais, que possui odor agradável, é de fácil manipulação e livre de patógenos, podendo ser utilizado na agricultura (FERNANDES \& SILVA, 2006; MONTEIRO et al., 2001; PEDROSA et al., 2013).

Quando incorporado ao solo, o mesmo pode aumentar a capacidade de troca iônica, o fornecimento de nutrientes complexos e aumentar o poder-tampão (PERREIRA NETO, 2011). Enquanto que nas características físicas pode-se observar que as substâncias húmicas coloidais atuam na formação de agregados estáveis no solo, juntamente com o fato de ser fonte energética para os micro-organismos, havendo assim melhoras na estrutura do solo, na aeração e permeabilidade, na resistência e retenção de água, redução das oscilações de temperatura, controle de erosão.

Além de poder ser usado como adubo orgânico, o composto orgânico pode ser comercializado como fertilizante orgânico desde que atenda as especificações determinadas na Instrução Normativa $\mathrm{n}^{\circ} 25$ do Ministério da Agricultura, Pecuária e Abastecimento (MAPA), de 23 de julho de 2009, onde são apresentadas as classes e os padrões de qualidade específicos, que estão diretamente vinculados a origens das matérias-primas utilizadas em sua produção (MAPA, 2009). Ainda em observância da qualidade do solo, o Conselho Nacional do Meio Ambiente (CONAMA) apresenta a Resolução ${ }^{\circ}$ 420 de 28 de dezembro de 2009, que dispõe sobre critérios e valores orientadores de qualidade do solo quanto à presença de substâncias químicas (CONAMA, 2009).

Com base nas informações apresentadas, o presente estudo foi desenvolvido com o objetivo de avaliar o processo de compostagem utilizando lodo flotado da Estação de Tratamento de Efluentes de Laticínio.

\section{Materiais e Métodos}

O presente estudo foi realizado em área experimental da Universidade Federal de Santa
Maria, campus Frederico Westphalen, na região do Médio Alto Uruguai do Rio Grande do Sul, no período de abril a julho de 2013. De acordo com Streck et al., (2008) o clima da região é subtropical úmido, segundo a classificação climática de Köppen-Geiger, com temperaturas mínimas próximas a $0^{\circ} \mathrm{C}$ no inverno e temperaturas máximas próximas a $40^{\circ} \mathrm{C}$ no verão. A precipitação média anual é elevada, variando entre 1800 e $2100 \mathrm{~mm}$, bem distribuídos nos meses do ano (BERNARDI et al., 2007).

$\mathrm{O}$ experimento foi realizado em triplicata, constituindo-se de três pilhas de compostagem. A fonte de nitrogênio utilizada foi o lodo flotado, proveniente do Sistema de Tratamento de Efluentes de Laticínio, enquanto a fonte de carbono orgânico utilizada foi o feno do capimtifton 85 (Cynodon ssp), que apresenta relação $\mathrm{C} / \mathrm{N}$ de 35 (AZEVEDO \& SPEHAR, 2002).

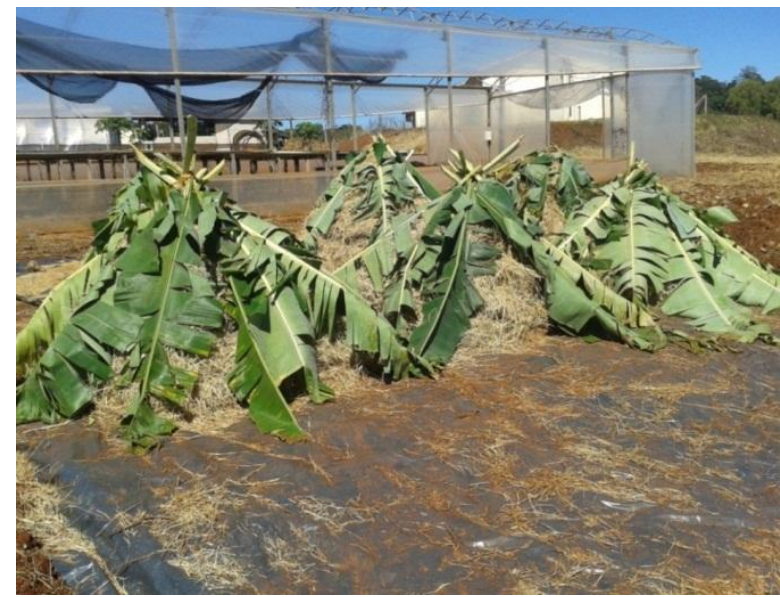

Figura 1 - Pilhas de compostagem após a montagem. UFSM, Campus de Frederico Westphalen, 2013

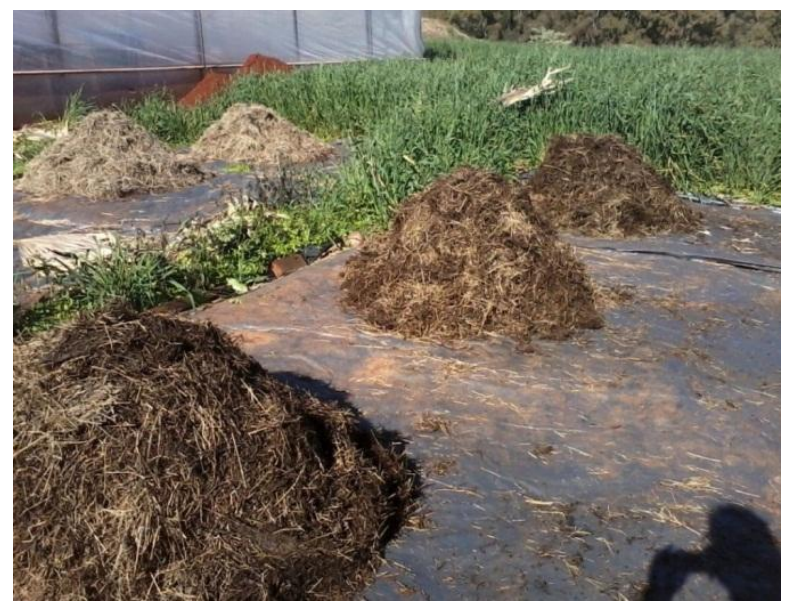

Figura 2 - Pilhas de compostagem após o revolvimento. UFSM, Campus de Frederico Westphalen, 2013 
As pilhas de compostagem foram montadas, após o nivelamento e impermeabilização do terreno, com alternância de camadas sendo 30\% do volume de resíduos orgânicos como fonte de nitrogênio e $70 \%$ do volume de resíduos com fonte de carbono. Foram construídas no formato de pirâmide, com a base quadrada de $1,5 \mathrm{~m}$ de lado 1,0 m de altura (Figura 1), sendo revolvidas (Figura 2) e umedecidas periodicamente.

Durante o processo foi realizado o monitorado da temperatura das pilhas, por intermédio do uso de termômetros de mercúrio, com intervalos regulares de dois dias na primeira fase, e posteriormente as medições foram realizadas a cada cinco dias. Nesse período também foi realizado o monitoramento das variáveis climatológicas e observados parâmetros como: insetos, fungos, aranhas, minhocas, larvas e odor, sendo atribuídas notas de acordo com a intensidade da presença do parâmetro, sendo: 0 (ausente), 1 (baixa), 2 (média), 3 (alta) ou 4 (muito alta). A finalidade do monitoramento foi encontrar a relação e a influência destes parâmetros nas temperaturas das pilhas, durante o processo.

Após a maturação do composto, avaliada pelo teste de maturação, descrito em Oliveira et al., (2008), foram coletadas amostras em cada pilha de compostagem através da técnica de quarteamento, conforme a NBR 10.007 (ABNT, 2004), e acondicionadas em sacos de amostragem devidamente identificados.

Posteriormente, as amostras foram secas a $65^{\circ} \mathrm{C}$, trituradas, homogeneizadas e quantificadas os teores de carbono orgânico total (COT) por combustão úmida (Walkey Black) com dicromato de potássio e ácido sulfúrico na presença de calor externo e titulação com sulfato ferroso amoniacal; nitrogênio total $(\mathrm{N})$ por digestão úmida com ácido sulfúrico e titulação após destilação pelo método do microdestilador (Kjeldahl); fósforo $(\mathrm{P})$, potássio $(\mathrm{K})$, cálcio $(\mathrm{Ca})$, magnésio $(\mathrm{Mg})$, sódio $(\mathrm{Na})$ por digestão úmida com ácido sulfúrico e determinação por espectrofotometria com azul-de-molidênio ( $\mathrm{P}$ ), fotometria de chama ( $\mathrm{K}$ e $\mathrm{Na}$ ) e espectrometria de absorção atômica (Ca e Mg); enxofre (S), cobre $(\mathrm{Cu})$, zinco $(\mathrm{Zn})$, ferro $(\mathrm{Fe})$ e manganês $(\mathrm{Mn})$ por digestão úmida nitro-perclórica e determinação por espectrofotometria (S) e espectrometria de absorção atômica (Cu, Zn, Fe e Mn); boro (B) por incineração a $550^{\circ} \mathrm{C}$ e determinação por espectrofotometria. As análises químicas foram realizadas pelo Laboratório de Química da Faculdade de Agronomia "Eliseu Maciel"UFPel, 2013.

\section{Resultados e Discussão}

\subsection{Temperatura}

O monitoramento da temperatura das pilhas é indicativo da eficiência do processo de compostagem. A partir deste, foram confrontados as temperatura das pilhas com os registros da temperatura ambiente e da precipitação pluviométrica (Figura 3).

O hidrograma demostra que as temperaturas, ambiente e média das pilhas, registraram declínios nos períodos de maior pluviometria. Apesar da pluviometria do período estar dentro das médias históricas, estes declínios podem ter sido altamente influenciados pelo fato de o experimento estar localizado em local aberto, sujeito as intempéries.

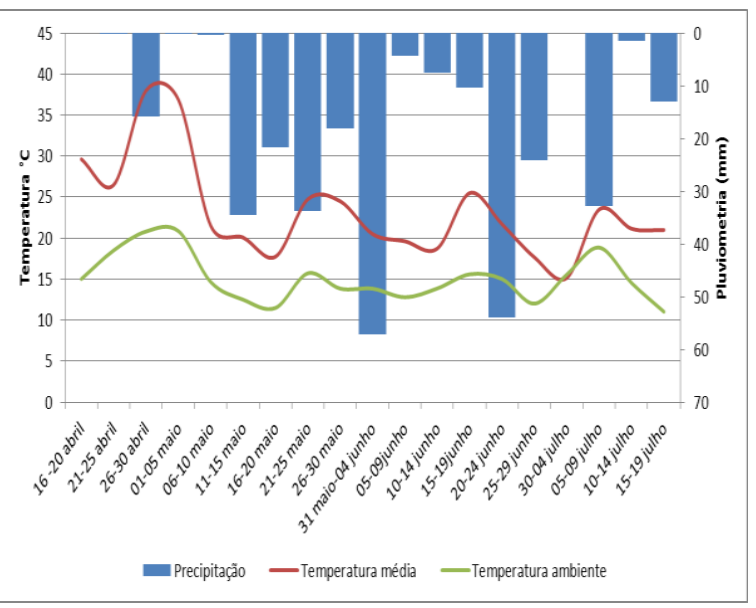

Figura 3 - Influência das variáveis climáticas na temperatura do processo de compostagem. UFSM/Campus FW, 2013

Também é visível a relação entre a temperatura ambiente e a temperatura média das pilhas, que devido ao experimento ser realizado em local de clima subtropical, no período de outono/inverno, não registrou altas temperaturas, com exceção das primeiras semanas. As temperaturas elevadas nas primeiras semanas são a combinação da baixa pluviometria e principalmente pela intensa atividade microbiana. Segundo Valente et al., 
(2009), os microrganismos são responsáveis pelo aumento da temperatura no processo de compostagem.

Também foram realizados revolvimentos das pilhas nos dias 26/abril, 10/maio, 27/maio, 12/junho, buscando a difusão do oxigênio que é altamente importante para suprir a demanda de oxigênio dos microrganismos decompositores. Apesar de uma pequena sensibilização e aumento das temperaturas nesses dias e/ou nos dias seguintes, este aumento não representou impacto significativo no processo em geral.

De acordo com Penteado (2006), o excesso de umidade é prejudicial à massa em fermentação, pois a água em excesso ocasiona a aglutinação de partículas, o que baixa a resistência estrutural da pilha dificultando assim a difusão de oxigênio. Uma vez que a matéria orgânica decomposta é hidrófila, as moléculas de água se aderem fortemente à superfície das partículas, ocorrendo a saturação dos seus micro e macro poros, tornando o processo anaeróbio, e retardando a decomposição do resíduo (MONTEIRO et al., 2001; PENTEADO, 2006).

Em relação às fases de decomposição do processo de compostagem, verificadas pela temperatura das pilhas, observa-se que a fase mesófila, primeira fase da decomposição, ocorreu já nos primeiros dias onde a temperatura média das pilhas não ultrapassou os $40^{\circ} \mathrm{C}$. Penteado (2006) salienta que nessa fase a temperatura não ultrapassa os $45^{\circ} \mathrm{C}$.

Na terceira semana houve o segundo pico de elevação da temperatura, o que pode ser associado com o aumento da temperatura ambiente e uma precipitação satisfatória, para manter a umidade em torno de 50\%, caracterizando o início de uma fase termófila, segunda fase do processo. Contudo a fase termófila não foi atingida, devido às temperaturas das pilhas não alcançarem valores entre 45 e $65^{\circ} \mathrm{C}$, e a atividade microbiológica ter decaído. O pequeno volume das pilhas pode ter contribuído para a menor concentração de calor, pois o aquecimento desta também está relacionado às suas dimensões (KIEHL, 1985). Enquanto que pilhas altas submetem as camadas inferiores aos efeitos da compactação, as pilhas baixas perdem calor mais facilmente ou nem aquecem o suficiente (PEREIRA NETO, 2004).

Outro fator interferente foi o estado inicial do lodo flotado: líquido e diluído. Apesar do lodo de laticínio apresentar alta carga orgânica, essas condições interferiram na atividade microbiana das pilhas de compostagem fazendo com que a temperatura não elevasse aos padrões característicos de uma fase termófila.

Com a diminuição da temperatura ambiente, na quarta semana, cerca de $12^{\circ} \mathrm{C}$, as pilhas de compostagem esfriaram bruscamente, passando de aproximadamente $40^{\circ} \mathrm{C}$ para temperaturas inferiores à $20^{\circ} \mathrm{C}$. Após este episódio as temperaturas das pilhas se mantiveram baixas até o final do processo de monitoramento, não ultrapassando os $30^{\circ} \mathrm{C}$. Comparando-se com a temperatura ambiente, ambas apresentaram comportamento similar, o que pode ser explicado pela baixa atividade microbiana, por falta de temperaturas ideais para o processo e pelas características do material orgânico utilizado.

O processo de compostagem não chegou à fase criófila, a qual é responsável pela humificação total da matéria orgânica (RODRIGUES et al., 2014), o que é comprovado pela relação $\mathrm{C} / \mathrm{N}$ final de 18:1, que confirma que o composto apenas atingiu a estabilização.

\subsection{Outras variáveis}

Além do monitoramento da temperatura ambiente, temperatura das pilhas e a precipitação pluviométrica, foram monitorados outros parâmetros como: odor, presença de insetos, aracnídeos, anelídeos e fungos. As variáveis receberam valores de intensidade quanto maior a presença, apresentando uma média mensal, conforme Figura 4.

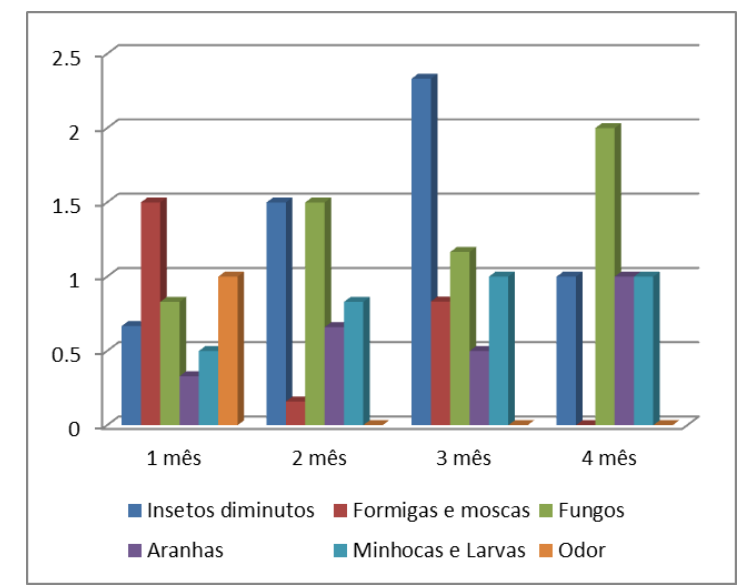

Figura 4 - Parâmetros monitorados durante o processo de compostagem. UFSM/Campus FW, 2013 
A presença de moscas (Diptera), formigas (Hymenoptera), larvas de insetos (Insecta) e minhocas (Haplotaxida) foi registrada em todas as etapas, porém com intensidade baixa. A variável com presença de maior intensidade ao longo do processo foi o Fungos. Segundo Pelczar (1980), os fungos são organismos heterotróficos, que obtém sua alimentação a partir da matéria orgânica inanimada. Os microrganismos saprófitas, decompõem resíduos complexos de plantas e animais, transformando-os em formas químicas mais simples.

Outra variável de destaque foi a de Insetos diminutos, sendo que o principal inseto encontrado foi o cascudinho (Coleopetara Tenebrionidae), notado a partir da metade do primeiro mês, em crescente quantidade e elevada intensidade. Abreu (2009) afere que os cascudinhos são insetos favoráveis ao processo de compostagem, onde atuam na decomposição da matéria orgânica.

$\mathrm{O}$ odor foi presenciado apenas no primeiro mês e com pouca intensidade. A coloração das pilhas, inicialmente amarela clara, escureceu ao longo do processo, chegando a tonalidades de marrom acinzentado ao final do monitoramento.

\subsection{Nutrientes}

Como principal resultado do processo de compostagem, o composto orgânico resultante é rico em nutrientes essenciais para as plantas, de forma a permitir que este venha a ser utilizado como fertilizante orgânico.

O fertilizante orgânico é um produto obtido por processo físico, químico, físico-químico ou bioquímico, natural ou controlado, a partir de matérias-primas de origem industrial, urbana ou rural, animal ou vegetal, isoladas ou misturadas, podendo ser enriquecido de nutrientes minerais, princípio ativo ou agente capaz de melhorar suas características físicas, químicas ou biológicas (MAPA, 2009). Com base nesta definição, o composto orgânico de lodo flotado de laticínio é classificados como "Classe A" (produção a partir de matéria-prima vegetal, animal, ou provindas de agroindústria, sem uso de sódio, metais pesados, elementos ou compostos orgânicos sintéticos potencialmente tóxicos).

Os elementos Nitrogênio (N), Fósforo $(\mathrm{P})$ e Potássio (K) são macronutrientes primários enquanto os elementos Cálcio (Ca), Magnésio (Mg) e Enxofre (S), secundários (MAPA, 2009).
Os teores desses nutrientes no composto orgânico são apresentados na Tabela 1.

Tabela 1 - Teores totais de nitrogênio $(\mathrm{N})$, fósforo $(\mathrm{P})$, potássio $(\mathrm{K})$, cálcio $(\mathrm{Ca})$, magnésio $(\mathrm{Mg})$ e enxofre $(S)$ presentes nos compostos orgânicos provenientes da compostagem de resíduos orgânicos. UFSM, Campus de Frederico Westphalen, 2013

\begin{tabular}{ccc}
\hline Macronutrientes & $\mathbf{( g ~ k g}^{-\mathbf{1}} \mathbf{)}$ & $\mathbf{V R}^{(\mathbf{1})}$ \\
\hline $\mathrm{N}$ & 23,0 & 5,0 \\
$\mathrm{P}$ & 4,0 & $\mathrm{nd}$ \\
$\mathrm{K}$ & 8,0 & $\mathrm{nd}$ \\
$\mathrm{Ca}$ & 6,7 & 10 \\
$\mathrm{Mg}$ & 2,4 & 10 \\
$\mathrm{~S}$ & 3,4 & 10 \\
\hline
\end{tabular}

(1) Valores de Referência $\left(\mathrm{g} \mathrm{kg}^{-1}\right)$ para fertilizantes orgânicos conforme o Ministério da Agricultura, Pecuária e Abastecimento (MAPA, 2009)

O Nitrogênio (N), o Fósforo (P) e o Potássio $(\mathrm{K})$, são os elementos essenciais às plantas sendo requisitados em quantidades elevadas em relação aos demais macronutrientes (EMPRAPA, 2013). O teor de $\mathrm{N}$ obtido, $23,0 \mathrm{~g} \mathrm{~kg}^{-1}$ foi superior a $5 \mathrm{~g} \mathrm{~kg}^{-1}$, estabelecido como mínimo para fertilizantes orgânicos (MAPA, 2009), indicando que a montagem das pilhas de compostagem (30\% do volume de material orgânico e $70 \%$ de feno do capim-tifton 85 (Cynodon ssp)) foram adequados para a produção de adubo orgânico no processo de compostagem. Já quanto ao teor de $\mathrm{P}$ foi de $4 \mathrm{~g} \mathrm{~kg}^{-1}$, apesar de não haver um valor de referência determinado pelo MAPA, Reis (2005) relata que lodos de diversos processos possuem quantidades consideráveis de $\mathrm{P}$ e outros nutrientes, que podem valorizar o seu potencial fertilizante.

No caso do $\mathrm{K}$, teor $8 \mathrm{~g} \mathrm{~kg}^{-1}$, este também não possui valor de referência determinado pelo MAPA. O valor não tão elevado pode ser explicado pelo fato de o $K$ não faz parte da constituição de compostos orgânicos e a sua presença ocorre na forma de íon $\mathrm{K}^{+}$dentro das plantas. Isto faz com que o nutriente seja liberado, em ambiente úmido, antes mesmo da mineralização do resíduo orgânico. As irrigações periódicas nas pilhas de compostagem provavelmente deslocaram o íon por fluxos preferenciais de água, resultando em valores não tão elevados, apesar do revolvimento frequente. 
Os teores de $\mathrm{Ca}, \mathrm{Mg}$ e $\mathrm{S}$, foram respectivamente $6,7 \mathrm{~g} \mathrm{~kg}^{-1}, 2,4 \mathrm{~g} \mathrm{~kg}^{-1}$ e 3,4 $\mathrm{g} \mathrm{kg}^{-1}$, estando todos abaixo do valor mínimo para fertilizante orgânico, que é $10 \mathrm{~g} \mathrm{~kg}^{-1}$ (MAPA, 2009). Costa et al., (2009), ao analisar os teores de Ca em compostos de resíduos sólidos de frigoríficos obtidos pelo processo de compostagem encontraram valores entre 5 e $10 \mathrm{~g}$ $\mathrm{kg}^{-1}$, resultados esses que se assemelham ao presente estudo.

Tabela 2 -. Teores totais de boro (B), cobre $(\mathrm{Cu})$, zinco $(\mathrm{Zn})$, ferro $(\mathrm{Fe})$, manganês $(\mathrm{Mn})$ e sódio

(Na) presentes nos compostos orgânicos

provenientes da compostagem de resíduos

orgânicos. UFSM, Campus de Frederico Westphalen, 2013

\begin{tabular}{ccc}
\hline Micronutrientes & $\left.\mathbf{( m g ~ k g}^{-1}\right)$ & VR $^{(\mathbf{1})}$ \\
\hline $\mathrm{B}$ & 15,1 & 300 \\
$\mathrm{Cu}$ & 44,6 & 500 \\
$\mathrm{Zn}$ & 104,7 & 1000 \\
$\mathrm{Fe}$ & 2372,0 & 2000 \\
$\mathrm{Mn}$ & 551,9 & 500 \\
$\mathrm{Na}$ & 180,0 & $\mathrm{nd}$ \\
\hline
\end{tabular}

(1) Valores de referência para fertilizantes orgânicos conforme o Ministério da Agricultura, Pecuária e Abastecimento (MAPA, 2009)

Dentre os micronutrientes analisados: Boro (B), Cobre $(\mathrm{Cu})$, Ferro (Fe), Manganês $(\mathrm{Mn})$, Zinco (Zn) e Sódio (Na), os elementos Fe e Mn superaram os teores mínimos estabelecidos pela Instrução Normativa no 25 (MAPA, 2009) para fertilizantes orgânicos (Tabela 2). Destacou-se o elemento Fe com maior valor, e acima do mínimo estabelecido pela Instrução Normativa no 25 (MAPA, 2009), que pode ser explicado pelo uso de feno do capim-tifton 85 (Cynodon ssp) como fonte de Carbono no processo de compostagem. Segundo Silva (2011), os altos teores de $\mathrm{Fe}$ encontrados na parte aérea de gramíneas é atribuído ao seu alto teor no Latossolo Vermelho Distrófico, solo predominante no município do estudo.

Comparando-se com os teores apresentados por Neto (2011) para os elementos: B (3,1 mg kg$\left.{ }^{1}\right), \mathrm{Cu}\left(12,40 \mathrm{mg} \mathrm{Kg}^{-1}\right)$, Fe $\left(210,40 \mathrm{mg} \mathrm{Kg}^{-1}\right)$ e $\mathrm{Mn}$ $\left(77,30 \mathrm{mg} \mathrm{Kg}^{-1}\right)$, os valores obtidos utilizando-se o lodo de efluentes de laticínio apresentaram-se muito superiores a estes.

Os micronutrientes $\mathrm{B}, \mathrm{Cu}$ e $\mathrm{Zn}$ apresentaram valores abaixo do mínimo estabelecido para fertilizantes orgânicos, segundo a Instrução Normativa no 25 (MAPA, 2009), contudo os elementos $\mathrm{Cu}$ e $\mathrm{Zn}$ apesar de serem essenciais para o crescimento das plantas também são metais que podem poluir o solo e a água. No Rio Grande do Sul, a portaria no 85 (FEPAM, 2014), estabelece valores de referência para solos com base nas províncias geomorfológicas do Estado, com limites máximos de $203 \mathrm{mg} \mathrm{kg}^{-1}$ de Cu e 120 $\mathrm{mg} \mathrm{kg}{ }^{-1}$ de $\mathrm{Zn}$ para os solos originados de rochas ígneas da região do planalto, estando os valores de $\mathrm{Cu}$ e $\mathrm{Zn}$ dentro dos valores estabelecidos. Nesse sentido são necessários critérios para evitar a contaminação do solo com $\mathrm{Cu}$ e $\mathrm{Zn}$ com o uso frequente de compostos orgânicos como fertilizante. Além disso, deve ser monitorado o uso do composto orgânico como substratos, principalmente para a produção de mudas de frutíferas e olerícolas.

Não houve diferença significativa para os teores de $\mathrm{Na}$ nos compostos orgânicos, com valores médios $180 \mathrm{mg} \mathrm{kg}^{-1}$. Apesar de não possuir valor mínimo de referência para fertilizante orgânico, segundo o MAPA (2009), o valor de $\mathrm{Na}$ não é considerado elevado, o qual pode ter sido perdido pela sistemática de umedecimento das leiras, onde os hidrogênios presentes na água são adsorvidos pelas micelas coloidais húmicas, que liberam outros cátions, o que explicaria a redução da disponibilidade deste componente nos resultados finais (REIS, 2005).

\subsection{Relação $\mathrm{C} / \mathrm{N}$}

A relação $\mathrm{C} / \mathrm{N}$ é um parâmetro importante para caracterizar o composto, pois indica a forma como o material orgânico se encontrou no final do processo de compostagem. O composto é bioestável quando a relação $\mathrm{C} / \mathrm{N}$ está em torno de 18 e humificado quando a atinge valores próximos de 10 (SILVA, 2011). De acordo com Oliveira et al., (2008), a relação $\mathrm{C} / \mathrm{N}$ ideal no início do processo é próxima de 30, para atingir valores próximos de 10 no final do processo de compostagem, após dois terços do carbono serem utilizados pelos microrganismos como energia e liberado na forma de $\mathrm{CO}_{2}$.

O composto orgânico final apresentou teor de COT total $440,9 \mathrm{~g} \mathrm{~kg}^{-1}$ e relação Carbono/Nitrogênio (C/N) de 18,67, conforme Tabela 4. Essa relação $\mathrm{C} / \mathrm{N}$ indica que $\mathrm{o}$ composto se encontrava bioestável, porém 
não humificado. A instrução normativa $n^{\circ} 25$ (MAPA, 2009) destaca que o teor mínimo COT exigido para fertilizantes orgânicos é de $150 \mathrm{~g} \mathrm{~kg}^{-1}$ e a relação C/N máxima de 20 . Com base nestes valores, o composto orgânico está adequado para uso como fertilizante orgânico na agricultura. A relação $\mathrm{C} / \mathrm{N}$ também é importante no uso dos compostos orgânicos como substratos para a produção de mudas.

Tabela 3. Teores totais de boro (B), cobre $(\mathrm{Cu})$, zinco $(\mathrm{Zn})$, ferro $(\mathrm{Fe})$, manganês $(\mathrm{Mn})$ e sódio

(Na) presentes nos compostos orgânicos provenientes da compostagem de resíduos orgânicos. UFSM, Campus de Frederico Westphalen, 2013.

\begin{tabular}{cc}
\hline Atributo Químico & Resultado \\
\hline COT & $440,9 \mathrm{~g} \mathrm{~kg}^{-1}$ \\
$\mathrm{~N}$ & $23,019 \mathrm{~g} \mathrm{~kg}^{-1}$ \\
$\mathrm{C} / \mathrm{N}$ & 18,67 \\
\hline
\end{tabular}

A elevada relação $\mathrm{C} / \mathrm{N}$ não permite que as mudas se desenvolvam vigorosamente, devido à imobilização do $\mathrm{N}$ disponível no substrato pelos microrganismos (ANDREANI JUNIOR et al., 2011) e a menor disponibilidade de outros nutrientes afetada pelo processo de mineralização (MEDEIROS et al., 2010).

\section{Conclusão}

O desenvolvimento do processo durante o outono/inverno e as ocorrências de períodos chuvosos, fez com que a temperatura das pilhas acompanhasse a temperatura ambiente, somente alcançando temperaturas mais altas nos períodos sem precipitações pluviométricas significativas. $\mathrm{O}$ aumento da umidade, mesmo com o revolvimento periódico, fez com que a aeração nas pilhas diminuísse, causando interferência na degradação biológica do composto.

O substrato resultante apresentou boa relação C/N 18,67, abaixo do valor máximo permitido pela Instrução Normativa $n^{\circ} 25$ (MAPA, 2009) (máximo de $\mathrm{C} / \mathrm{N} 20$ ), estando assim, adequado para uso como fertilizante orgânico na agricultura. Apesar da relação $\mathrm{C} / \mathrm{N}$ ser adequada, o processo de compostagem não atingiu a temperatura ideal para eliminação de microrganismos patógenos e sementes.

O composto orgânico também atingiu valores satisfatórios e dentro dos valores estabelecidos pela legislação, para fertilizantes orgânicos, para os macronutrientes $\mathrm{N}, \mathrm{P}, \mathrm{K}$ e para os micronutrientes $\mathrm{Fe}, \mathrm{Mn}$ e $\mathrm{Na}$. Já os nutrientes $\mathrm{Ca}$, $\mathrm{Mg}, \mathrm{S}, \mathrm{B}, \mathrm{Cu}$ e $\mathrm{Zn}$ apresentaram valores abaixo do mínimo estabelecido pela legislação, o que não impossibilita o uso do composto como fertilizante orgânico, desde que realizada a suplementação dos macro e micronutrientes em deficiência.

\section{Recomendações}

É recomendável, para aperfeiçoamento deste estudo, a utilização do lodo de laticínio o mais concentrado possível, a fim de que seja mantida uma carga orgânica representativa do material. Outro fator que deve ser observado é a temperatura ambiente, sendo recomendável a realização desse processo em estações quentes para regiões subtropicais. Essas duas recomendações podem resultar no alcance da fase criófila e humidificação do composto orgânico final.

\section{Referências}

ABREU PG, PAIVA DP, ABREU VMN, COLDEBELLA A. Casca de arroz e palhada da soja como substrato para compostagem de carcaças de frangos de corte. Concórdia: EMBRAPA. 2009.

ANDREANI JÚNIOR R, ANDREANI DIK, LUISON EA, SILVA EG, GIMENEZ JI. Diferentes compostos orgânicos como substratos para produção de mudas de tomate. Revista Pesquisa em Foco. 2011;19(1):42-52.

BERNARDI IP, PULCHÉRIO-LEITE A, IRANDA, JMD, PASSOS FC. Ampliação da distribuição de Molossops neglectus Williams e Genoways (Chiroptera, Molossidae) para o Sul da América do Sul. Revista Brasileira de Zoologia. 2007;24(2):505-507. 
FAGUNDES DC. Gerenciamento de resíduos sólidos urbanos em Tarumã e Teodoro Sampaio - SP. Revista Sociedade e Natureza. 2009;21(2):159-179.

PORTARIA FEPAM N. 85 DE 05 DE SETEMBRO DE 2014. Dispõe sobre o estabelecimento de Valores de Referência de Qualidade (VRQ) dos solos para 09 (nove) elementos químicos naturalmente presentes nas diferentes províncias geomorfológicas/geológicas do Estado do Rio Grande do Sul. Diário Oficial da União (Brasília). 2014 set 05.

FERNANDES F, SILVA SMCP. Manual prático para a compostagem de biossólidos. Londrina: PROSAB; 2006.

GOPINATHAN M, THIRUMURTHY M. Feasibility Studies on Static Pile Co Composting of Organic Fraction of Municipal Solid Waste With Dairy Waste Water. 2012;2(2):34-39.

GUANZIROLI CE. Agroindústria Rural no Brasil: experiências bem e mal sucedidas. Niterói: Universidade Federal Fluminense; 2010.

INÁCIO CT, MILLER PRM. Compostagem: ciência e prática para a gestão de resíduos orgânicos. Rio de Janeiro: EMBRAPA; 2009.

KIEHL EJ. Fertilizantes orgânicos. Sao Paulo: Ceres; 1985.

KIEHL EJ. Manual da Compostagem: maturação e qualidade do composto. São Paulo: Universidade de São Paulo; 2002.

LONGHURST RD, ROBERTS AHC, O'connor MB. Farm dairy effluent: A review of published data on chemical and physical characteristics in New Zealand. New Zealand Journal of Agricultural Research. 2010;43(1): 7-14.
INSTRUÇÃO NORMATIVA MAPA N. 25, DE 23 DE JULHO DE 2009. Aprova as normas sobre as especificações e as garantias, as tolerâncias, o registro, a embalagem e a rotulagem dos fertilizantes orgânicos simples, mistos, compostos, organominerais e biofertilizantes destinados à agricultura. Diário Oficial da União (Brasília). 2009 jul 28.

MATOS, A.T. Tratamento de resíduos agroindustriais. Fundação Estadual do Meio Ambiente. Viçosa: Universidade Federal de Viçosa; 2005.

MEDEIROS ADAS, SILVA EGDA, LUISON EA, ANDREANI JUNIOR R, KOUZSNYANDREANI DI. Utilização de compostos orgânicos para uso como substratos na produção de mudas de alface. Revista Agrarian. 2010;3(10):261-266.

MONTEIRO JHP, FIGUEIREDO CEM, MAGALHÃES AF, MELO MAF, BRITO JCX, ALMEIDA TPF, et al. Manual de Gerenciamento Integrado de resíduos sólidos. Rio de Janeiro: IBAM; 2001.

MUSTAPHA I. 2013. Composting by households in. Environment Accounts and Statistics Division. n. 16, Canadá. 2013. Disponível a partir de: http://www.statcan.gc.ca/pub/16-002x/2013001/article/11848-eng.pdf [Internet] [citado em 31 de mar de 2014 ].

NIRENBERG LP, FERREIRA OM. Tratamento de águas residuárias de indústria de laticínios: eficiência e análise de modelos matemáticos do projeto da Nestlè. Goiânia: Universidade Católica de Goiás; 2005. 
NETO JTP, Manual de Compostagem: Processo de baixo custo. Universidade Federal de Viçosa: Minas Gerais; 2011.

PENTEADO SR, Adubação orgânica: Compostos orgânicos e Biofertilizantes. Campinas: Agrorgânica; 2006.

PEDROSA TD, FARIAS CAS, PEREIRA RA, FARIAS ETR. Monitoramento dos parâmetros físico-químicos na compostagem de resíduos agroindustriais. Revista Nativa. 2013;1(1):4448.

PELCZAR M. MICROBIOLOGIA. Sao Paulo: McGraw-Hill do Brasil, 1980.

PEREIRA NETO JT. Manual de Compostagem: Processo de baixo custo. Viçosa: Universidade Federal de Viçosa, 2007. 81p.

PRIMO DC, FADIGAS FS, CARVALHO JCR, SCHIMIDT CDS, BORGES FILHO ACS. Avaliação da qualidade nutricional de composto orgânico produzido com resíduos de fumo. Revista Brasileira de Engenharia Agrícola e Ambiental. 2010;14(7):742-746.

REIS MFP. Avaliação do processo de compostagem de resíduos sólidos urbanos [tese] Porto Alegre: Instituto de Pesquisas Hidráulicas/UFRGS; 2005. 239p.

RUSSO MAT. Tratamento de resíduos sólidos. Universidade Federal de Pernambuco, 2003. Disponível a partir de: http://homepage.ufp.pt/madinis/RSol/Web/T ARS.pdf [citado em 14 de abr 2014].

SCHALCH V, LEITE WCDEA, Fernandes Junior JL, Castro MCAA. Gestão e Gerenciamento de Resíduos Sólidos. São Carlos: Universidade de São Paulo; 2002.
STRECK EV, KÄMPF N, DALMOLIN RSD, KLAMT E, NASCIMENTO PCDO, SCHNEIDER P, et al. Solos do Rio Grande do Sul. Porto Alegre: EMATER/RS, 2008. 222p.

SILVA D. J. P. Resíduos na indústria de laticínio. Série Sistema de Gestão Ambiental. Minas Gerais: Universidade Federal de Viçosa; 2011.

UNITED STATES DEPARTMENT OF AGRICULTURE - USDA. 2005. Composting Dog Waste. Available from: http://waste.greenventure.ca/webfm_send/1. [Internet] [cited 2014 mar 31].

VALENTE BS, XAVIER EG, MORSELLI TBGA, JAHNKE DS, BRUM BDES, CABRERABR, ET al. 2009. Fatores que afetam o desenvolvimento da compostagem de resíduos orgânicos. Universidade de Cordoba. Disponível a partir de:http://www.uco.es/organiza/servicios/publ ica/az/php/img/web/07_18_48_1395REVISIO NFatoresValente1.pdf [Internet] [citado em 08 de jun de 2014]. 